\title{
Guideline update for the performance of fusion procedures for degenerative disease of the lumbar spine. Part 6: Discography for patient selection
}

\author{
Jason C. Eck, D.O., M.S., ${ }^{1}$ Alok Sharan, M.D., ${ }^{2}$ Daniel K. Resnick, M.D., ${ }^{3}$ \\ William C. Watters III, M.D., ${ }^{4}$ Zoher Ghogawala, M.D., 5 Andrew T. Dailey, M.D., ${ }^{6}$ \\ Praveen V. Mummaneni, M.D. ${ }^{7}$ Michael W. Groff, M.D., ${ }^{8}$ Jeffrey C. Wang, M.D., ${ }^{9}$ \\ Tanvir F. Choudhri, M.D., ${ }^{10}$ Sanjay S. Dhall, M.D. ${ }^{7}$ and Michael G. Kaiser, M.D. ${ }^{11}$ \\ ${ }^{1}$ Center for Sports Medicine and Orthopaedics, Chattanooga, Tennessee; ${ }^{2}$ Department of Orthopaedic \\ Surgery, Montefiore Medical Center, Albert Einstein College of Medicine, Bronx, New York; ${ }^{3}$ Department \\ of Neurosurgery, University of Wisconsin, Madison, Wisconsin; ${ }^{4}$ Bone and Joint Clinic of Houston, \\ Houston, Texas, ${ }^{5}$ Alan and Jacqueline Stuart Spine Research Center, Department of Neurosurgery, Lahey \\ Clinic, Burlington, and Tufts University School of Medicine, Boston, Massachusetts; ${ }^{6}$ Department of \\ Neurosurgery, University of Utah, Salt Lake City, Utah; ${ }^{7}$ Department of Neurological Surgery, University \\ of California, San Francisco, California; ${ }^{8}$ Department of Neurosurgery, Brigham and Women's Hospital, \\ Boston, Massachusetts; ' Department of Orthopaedic Surgery, Keck School of Medicine, University of \\ Southern California, Los Angeles, California; ${ }^{10}$ Department of Neurosurgery, Icahn School of Medicine at \\ Mount Sinai, New York; and ${ }^{l 1}$ Department of Neurosurgery, Columbia University, New York, New York
}

Identifying the etiology of pain for patients suffering from chronic low-back pain remains problematic. Noninvasive imaging modalities, used in isolation, have not consistently provided sufficient evidence to support performance of a lumbar fusion. Provocative testing has been used as an adjunct in this assessment, either alone or in combination with other modalities, to enhance the diagnostic capabilities when evaluating patients with low-back pain. There have been a limited number of studies investigating this topic since the publication of the original guidelines. Based primarily on retrospective studies, discography, as a stand-alone test, is not recommended to formulate treatment strategies for patients with low-back pain. A single randomized cohort study demonstrated an improved potential of discoblock over discography as a predictor of success following lumbar fusion. It is therefore recommended that discoblock be considered as a diagnostic option. There is a possibility, based on a matched cohort study, that an association exists between progression of degenerative disc disease and the performance of a provocative discogram. It is therefore recommended that patients be counseled regarding this potential development prior to undergoing discography.

(http://thejns.org/doi/abs/10.3171/2014.4.SPINE14269)

KEY WoRDS • fusion $\bullet$ lumbar spine $\quad \bullet \quad$ discography $・$ discoblock $\bullet$
practice guidelines

\section{Recommendations}

There is no evidence that conflicts with the previous recommendations published in the original version of the "Guidelines for the performance of fusion procedures for degenerative disease of the lumbar spine."

\section{Grade $C$}

It is recommended that discoblock be considered as a diagnostic option during the evaluation of a patient presenting with chronic low-back pain (single Level II study).

\footnotetext{
Abbreviations used in this paper: AAOS = American Academy of Orthopaedic Surgeons; JOA = Japanese Orthopaedic Association; MODEMS = Musculoskeletal Outcomes Data Evaluation and Management System; ODI = Oswestry Disability Index; VAS = visual analog scale.
}

It is recommended that lumbar discography not be used as a stand-alone test on which treatment decisions are based for patients with low-back pain with abnormal imaging studies (single Level II study).

It is recommended that within the discussion of potential risks for patients undergoing provocative discography, the potential for acceleration of the degenerative process be included as there is evidence to suggest an association between advanced degenerative spondylosis and a history of undergoing provocative discography.

\section{Rationale}

Surgical intervention for the treatment of chronic lowback pain has demonstrated inconsistent and less favorable results than procedures performed for other degenerative spine disorders. This is in part due to an inability to ac- 
curately determine the specific source of a patient's pain. It is well known that degenerative changes identified on an MRI may occur in asymptomatic patients, and therefore such findings cannot be used as the sole justification for surgery and are not predictive of clinical outcome. ${ }^{1}$

In an effort to isolate the source of pain, provocative testing (intended to reproduce a patient's pain), has been integrated into the evaluation of patients presenting with chronic low-back pain. Discography has been used in conjunction with MRI in an attempt to better identify specific patients who might benefit from lumbar fusion for chronic low-back pain. The purpose of this review is to examine the medical evidence regarding the utilization of discography as a diagnostic modality in the evaluation of patients presenting with chronic low-back pain being considered for lumbar spine fusion. Additional information regarding the methodologies and criteria used to evaluate the evidence discussed below is located in the first article in this issue (Part 1: Introduction and methodology). ${ }^{12}$

\section{Literature Search}

The database of the National Library of Medicine was searched for articles published between July 2003 and December 2011 using the following search terms: ((discography OR discogram) AND lumbar fusion AND (patient selection OR predictive value of tests) AND ((“2003”[PDat]: “3000”[PDat]) AND (Humans[MeSH]) AND (English[lang]))) OR ((discography OR discogram) AND (((“Lumbosacral Region”[MeSH] OR "Lumbar Vertebrae"[MeSH]) AND "Spinal Fusion"[MeSH]) OR "lumbar fusion"[All Fields] OR ("lumbar"[title] AND "fusion"[title])) AND (patient selection OR predictive value of tests) AND ((“2003”[PDat]: “3000”[PDat]) AND (Humans[MeSH]) AND (English[lang]))). Search results were limited to human studies, English language, and age between 18 and 65 years. The titles and abstracts of these articles were reviewed, and duplicates, technical notes, reviews, and papers that did not describe the use of discography for the diagnosis and management of patients with low-back pain were discarded. The reference lists of the remaining articles were inspected, and additional relevant papers were identified. From this group of citations, 6 were selected as the most relevant and are briefly described in the evidentiary table (see Table 1). The remaining references provided additional background information and are included in the bibliography.

\section{Scientific Foundation}

The use of discography for the diagnosis of lumbar intervertebral disc abnormalities in patients with low-back pain has been well described., ${ }^{915}$ The key components of discography that aid in the diagnosis of patients with lowback pain include a reproduction of the patient's concordant pain, visualization of the disc morphology, and injection pressures. If each of these factors is found to suggest symptomatic disc degeneration, the test is considered to be positive. By recreating the patient's pain, proponents of discography argue that it is more sensitive and specific than other imaging modalities, including plain radiographs, myelography, and MRI, which are known to identify both symptomatic and asymptomatic abnormalities. ${ }^{2-4}$ However, critics question the reliability and specificity of discography since concordant pain has been suggested to originate from nonspine sources and can be reproduced in patients without any prior history of back pain. ${ }^{5,8,11}$

A prospective study intended to evaluate the predictive value of provocative discography following lumbar fusion was performed by Carragee et al. ${ }^{7}$ Lumbar fusions were performed in 32 patients with presumed discogenic pain and a positive discogram (see Table 1). A circumferential fusion was performed in a single day and consisted of an anterior lumbar interbody fusion with femoral ring allograft, buttress screw, and local bone/ allograft inserted within and around the structural graft. The posterior approach included an intertransverse fusion with allograft and pedicle screw instrumentation. Clinical outcomes were measured using a visual analog scale (VAS), American Academy of Orthopaedic Surgeons (AAOS) Musculoskeletal Outcomes Data Evaluation and Management System (MODEMS) instrument, Oswestry Disability Index (ODI), psychological testing, and the Fear Avoidance and Behavior Questionnaire. Clinical success at the 2-year follow-up point was defined by a VAS score of 2 or less, an ODI score of less than 15 , return to work, no use of narcotic medications, and no daily pain medication requirement. Surgical comorbidity was compared with a control cohort of 34 patients undergoing lumbar fusion for unstable isthmic spondylolisthesis. Successful outcomes were observed in $72 \%$ of the control spondylolisthesis group as compared with only $27 \%$ in the discography group. The percentage of patients achieving a minimally acceptable improvement in the control group was $91 \%$ versus $43 \%$ for the discography group. The positive predictive value of discography was estimated to be between $50 \%$ and $60 \%$. This study suffered from several design limitations, including the lack of an appropriate control group and is therefore considered to provide only Level IV evidence against utility of discography as a predictive tool.

Wetzel et al. performed a retrospective case review of 48 patients with a diagnosis of discogenic low-back pain based on positive discography and CT or MRI. ${ }^{18}$ All patients underwent lumbar fusion of the levels determined to be symptomatic based on discography. The number of levels fused ranged from 1 to 4 , and a wide variety of fusion techniques were used, including anterior or posterior approaches, with or without instrumentation. Clinical outcomes were subjectively graded as excellent, good, fair, or poor. Radiographic evidence of fusion was defined as $4^{\circ}$ or less of motion on flexion-extension radiographs with the presence of mature trabecular bone across all levels. Twenty-three (47.9\%) went on to successful radiographic fusion, and 22 of those had a satisfactory clinical outcome. Overall, $46 \%$ of patients were found to have a satisfactory clinical outcome. This study provided Level IV evidence against the use of discography in predicting clinical success following lumbar spine fusion. Limitations of the study included a variety of surgical techniques and lack of quantitative and validated clinical outcomes measures (see Table 1).

A retrospective case series of 53 patients undergoing 
Part 6: Discography for patient selection

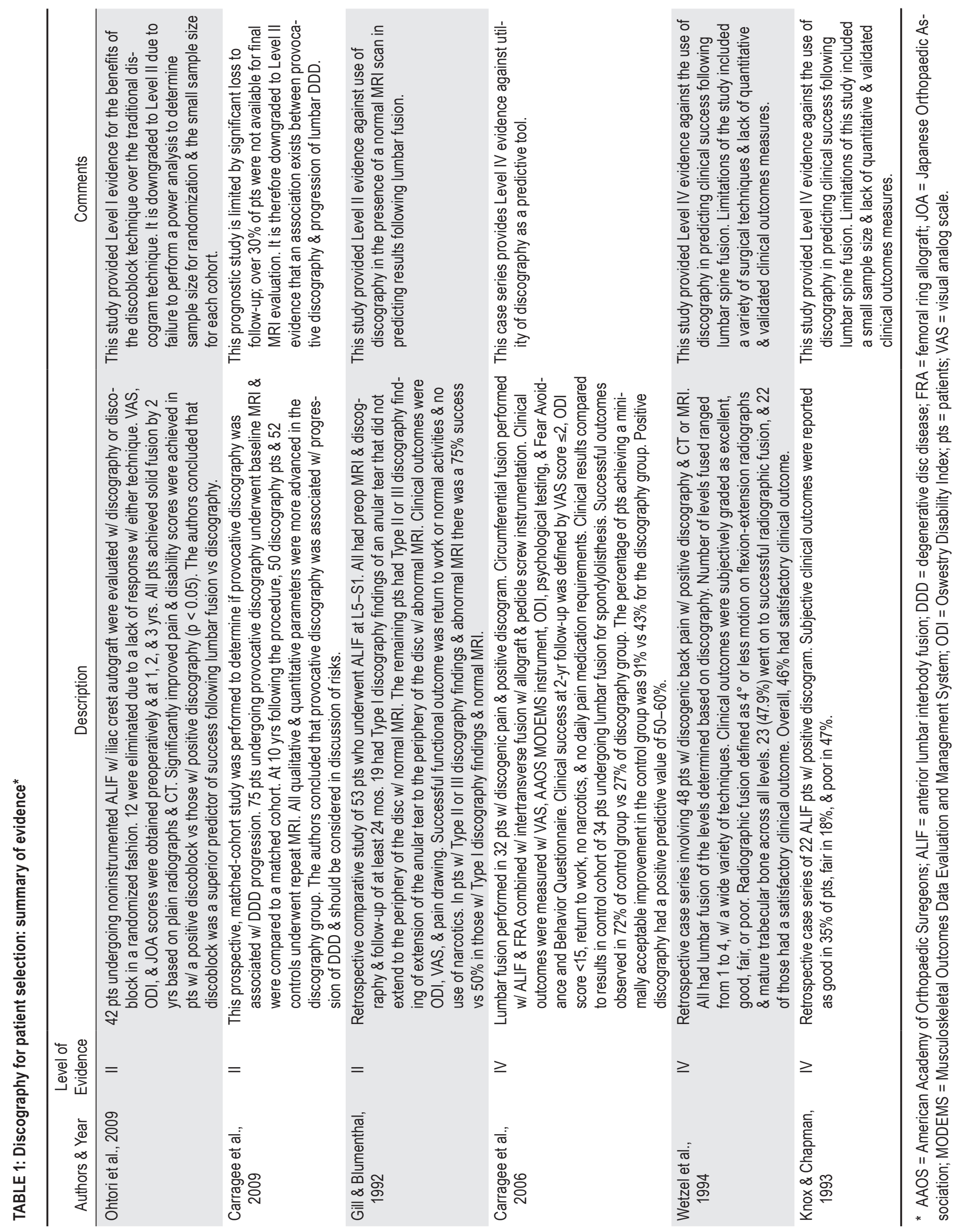


anterior lumbar interbody fusion at L5-S1 was performed by Gill and Blumenthal. ${ }^{10}$ All patients had preoperative MRI and discography and at least 24 months of follow-up. Nineteen of the patients had Type I discography findings of an anular tear that did not extend to the periphery of the disc with normal MRI findings. The remaining patients had a Type II or III discography finding of extension of the anular tear to the periphery of the disc with abnormal MRI findings. Clinical outcomes were measured by the "Oswestry Pain Questionnaire" (ODI), VAS, and a pain drawing. A successful functional outcome was defined as the ability to return to work or normal activities and no use of narcotic medications. In the patients with Type II or III discography findings and abnormal MRI findings, there was a $75 \%$ success rate postoperatively, while there was a 50\% success rate in those with Type I discography findings and normal MRI findings. This study provided Level IV evidence against the use of discography in the presence of normal MRI findings in predicting results following lumbar fusion. The limitations of this study include being a retrospective case series and having a small sample size (see Table 1).

Additional Level IV evidence against the use of discography for the prediction of clinical success following lumbar fusion was provided by Knox and Chapman. ${ }^{14}$ They performed a retrospective analysis of a case series involving 22 patients who had positive discogram findings and underwent anterior lumbar interbody fusion. Subjective clinical outcomes were reported as good in $35 \%$ of patients, fair in $18 \%$, and poor in $47 \%$. Limitations of this study included a small sample size and lack of quantitative and validated clinical outcomes measures.

Willems et al. conducted a retrospective review of a series of cases to determine whether preoperative discography of adjacent-level discs could predict clinical outcome in patients undergoing lumbar fusion. ${ }^{19}$ This study began with 209 patients, but 12 were eliminated for lack of data, and an additional 115 received conservative treatment. The remaining 82 patients had lumbar fusion and their cases were used in the analysis. Outcomes measures included a VAS pain scale and Odom's criteria. The preoperative discography results for adjacent levels did not affect clinical outcomes in this series of patients. This study provides Level IV evidence against the use of adjacent-level discography as a predictor of clinical success after lumbar fusion.

An alternative to the traditional technique of discography is the technique known as a "discoblock," which involves injecting the disc with an anesthetic agent instead of a contrast agent in an effort to eliminate as opposed to reproducing a patient's pain. This modified technique was compared with traditional discography by Ohtori et al. ${ }^{16}$ Forty-two patients undergoing a noninstrumented anterior lumbar interbody fusion with iliac crest autograft were evaluated preoperatively with either provocative discography or discoblock in a randomized fashion. Twelve patients were eliminated from the study due to a lack of response with either technique. Outcome measures including VAS, ODI, and Japanese Orthopaedic Association (JOA) scores were obtained preoperatively and at 1,2 , and 3 years postoperatively. All patients reportedly achieved a solid fusion by 2 years following surgery based on plain radiographs and CT scans. Significantly improved clinical outcomes with respect to both pain and disability scores were achieved following lumbar fusion in patients with positive discoblock findings as compared with those with positive discography findings $(\mathrm{p}<0.05)$. The authors suggested that the discoblock technique proved to be a better predictor of success following lumbar fusion than provocative discography. This study provided Level II evidence for the benefits of the discoblock technique over the traditional provocative discography. Limitations of the study included a small sample size and lack of a power analysis.

More recently, concern has developed over the possibility that diagnostic disc injections may lead to iatrogenic injury to the disc and accelerate the rate of disc degeneration. Animal studies have demonstrated degeneration of an intervertebral disc due to a needle puncture of the annulus fibrosis. ${ }^{13,17}$ Carragee et al. conducted a comparative prospective cohort study over a 10 -year period, during which they followed the progression of disc degeneration in patients with and without a history of discography ${ }^{6}$ MRI studies were performed at baseline and 10 years following provocative discography. Two blinded radiologists and 2 blinded orthopedic surgeons evaluated the images. All outcome measures, including progression of disc degeneration, occurrence of new herniations, loss of disc height, and loss of disc signal intensity, were found to be significantly worse in the patients who had undergone discography. Of the original sample cohort of 150 patients enrolled, only $68 \%$ were available at the time of follow-up. This study was classified as a prognostic study regarding the outcome after performance of a provocative discography and was downgraded to Level II evidence of the potential risk associated with the use of provocative discography due to the $32 \%$ loss to follow-up.

\section{Summary}

The use of discography to aid in patient selection for lumbar fusion remains controversial. Based on the current literature, there is insufficient evidence to suggest that discography should be used as an independent predictor of success following lumbar fusion for low-back pain. There is limited evidence to suggest that a discoblock or anesthetizing the disc instead of injecting contrast material provides superior predictive value. More recent evidence, however, suggests a possible risk of discography leading to an acceleration of disc degeneration.

\section{Key Issues for Further Investigation}

Determining the diagnostic potential of a specific test rests on the ability to compare results between a "gold standard" and the test under investigation. Due to the lack of a "gold standard" when attempting to identify the source of a patient's low-back pain, such evaluations are extremely difficult to design and interpret. With respect to discography, there remains insufficient evidence to support its routine use as a diagnostic modality when evaluating patients with low-back pain. While further investigation may help elucidate the potential of discog- 
raphy, such trials may not be feasible given the recent evidence that accelerated rates of disc degeneration are associated with a history of previous discograms.

\section{Acknowledgments}

We would like to acknowledge the AANS/CNS Joint Guidelines Committee (JGC) for their review, comments, and suggestions; Laura Mitchell, CNS Guidelines Project Manager, for her organizational assistance; and Linda O'Dwyer, medical librarian, for assistance with the literature searches. We would also like to acknowledge the following individual JGC members for their contributions throughout the review process: Timothy Ryken, M.D.; Kevin Cockroft, M.D.; Sepideh Amin-Hanjani, M.D.; Steven N. Kalkanis, M.D.; John O'Toole, M.D., M.S.; Steven Casha, M.D., Ph.D.; Aaron Filler, M.D., Ph.D., F.R.C.S.; Daniel Hoh, M.D.; Steven Hwang, M.D.; Todd McCall, M.D.; Jeffrey J. Olson, M.D.; Julie Pilitsis, M.D., Ph.D.; Joshua Rosenow, M.D.; and Christopher Winfree, M.D.

\section{Disclosure}

Administrative costs of this project were funded by the Congress of Neurological Surgeons and the Joint Section on Disorders of the Spine and Peripheral Nerves of the American Association of Neurological Surgeons and Congress of Neurological Surgeons. No author received payment or honorarium for time devoted to this project. Dr. Ghogawala receives grants from the Patient Centered Outcomes Research Institute (PCORI) and the National Institutes of Health (NIH). Dr. Groff is a consultant for DePuy Spine and EBI Spine. Dr. Mummaneni owns stock in Spinicity and receives honoraria from DePuy Spine and Globus and royalties from DePuy Spine, Quality Medical Publishers, and Thieme Publishing. Dr. Wang owns stock in Bone Biologics, AxioMed, Amedica, CoreSpine, Expanding Orthopedics, Pioneer, Syndicom, VG Innovations, PearlDiver, Flexuspine, Axis, FzioMed, Benvenue, Promethean, Nexgen, ElectroCore, and Surgitech and holds patents with and receives royalties from Biomet, Stryker, SeaSpine, Aesculap, Osprey, Amedica, Synthes, and Alphatec. The authors report no other potential conflicts of interest concerning the materials or methods used in this study or the findings specified in this paper.

Author contributions to the study and manuscript preparation include the following. Acquisition of data: all authors. Analysis and interpretation of data: all authors. Drafting the article: Eck. Critically revising the article: all authors. Reviewed submitted version of manuscript: all authors. Approved the final version of the manuscript on behalf of all authors: Eck. Study supervision: Kaiser.

\section{References}

1. Boden SD, McCowin PR, Davis DO, Dina TS, Mark AS, Wiesel S: Abnormal magnetic-resonance scans of the cervical spine in asymptomatic subjects. A prospective investigation. J Bone Joint Surg Am 72:1178-1184, 1990

2. Braithwaite I, White J, Saifuddin A, Renton P, Taylor BA: Vertebral end-plate (Modic) changes on lumbar spine MRI: correlation with pain reproduction at lumbar discography. Eur Spine J 7:363-368, 1998

3. Brightbill TC, Pile N, Eichelberger RP, Whitman M Jr: Normal magnetic resonance imaging and abnormal discography in lumbar disc disruption. Spine (Phila Pa 1976) 19:1075-1077, 1994

4. Brodsky AE, Kovalsky ES, Khalil MA: Correlation of radiologic assessment of lumbar spine fusions with surgical exploration. Spine (Phila Pa 1976) 16 (6 Suppl):S261-S265, 1991

5. Carragee EJ, Chen Y, Tanner CM, Truong T, Lau E, Brito
JL: Provocative discography in patients after limited lumbar discectomy: a controlled, randomized study of pain response in symptomatic and asymptomatic subjects. Spine (Phila Pa 1976) 25:3065-3071, 2000

6. Carragee EJ, Don AS, Hurwitz EL, Cuellar JM, Carrino JA, Herzog R: 2009 ISSLS Prize Winner: Does discography cause accelerated progression of degeneration changes in the lumbar disc: a ten-year matched cohort study. Spine (Phila Pa 1976) 34:2338-2345, 2009 [Erratum in Spine (Phila Pa 1976) $35: 1414,2010]$

7. Carragee EJ, Lincoln T, Parmar VS, Alamin T: A gold standard evaluation of the "discogenic pain" diagnosis as determined by provocative discography. Spine (Phila Pa 1976) 31:2115-2123, 2006

8. Carragee EJ, Tanner CM, Khurana S, Hayward C, Welsh J, Date $\mathrm{E}$, et al: The rates of false-positive lumbar discography in select patients without low back symptoms. Spine (Phila Pa 1976) 25:1373-1381, 2000

9. Collis JS Jr, Gardner WJ: Lumbar discography. An analysis of one thousand cases. J Neurosurg 19:452-461, 1962

10. Gill K, Blumenthal SL: Functional results after anterior lumbar fusion at L5-S1 in patients with normal and abnormal MRI scans. Spine (Phila Pa 1976) 17:940-942, 1992

11. Holt EP Jr: The question of lumbar discography. J Bone Joint Surg Am 50:720-726, 1968

12. Kaiser MG, Eck JC, Groff MW, Watters III WC, Dailey AT, Resnick DK, et al: Guideline update for the performance of fusion procedures for degenerative disease of the lumbar spine. Part 1: Introduction and methodology. J Neurosurg Spine 21:2-6, 2014

13. Kim KS, Yoon ST, Li J, Park JS, Hutton WC: Disc degeneration in the rabbit: a biochemical and radiological comparison between four disc injury models. Spine (Phila Pa 1976) 30:33-37, 2005

14. Knox BD, Chapman TM: Anterior lumbar interbody fusion for discogram concordant pain. J Spinal Disord 6:242-244, 1993

15. Lindblom K: Technique and results of diagnostic disc puncture and injection (discography) in the lumbar region. Acta Orthop Scand 20:315-326, 1951

16. Ohtori S, Kinoshita T, Yamashita M, Inoue G, Yamauchi K, Koshi T, et al: Results of surgery for discogenic low back pain: a randomized study using discography versus discoblock for diagnosis. Spine (Phila Pa 1976) 34:1345-1348, 2009

17. Sobajima S, Kompel JF, Kim JS, Wallach CJ, Robertson DD, Vogt MT, et al: A slowly progressive and reproducible animal model of intervertebral disc degeneration characterized by MRI, X-ray, and histology. Spine (Phila Pa 1976) 30:15-24, 2005

18. Wetzel FT, LaRocca SH, Lowery GL, Aprill CN: The treatment of lumbar spinal pain syndromes diagnosed by discography. Lumbar arthrodesis. Spine (Phila Pa 1976) 19:792-800, 1994

19. Willems PC, Elmans L, Anderson PG, van der Schaaf DB, de Kleuver M: Provocative discography and lumbar fusion: is preoperative assessment of adjacent discs useful? Spine (Phila Pa 1976) 32:1094-1100, 2007

Manuscript submitted March 13, 2014.

Accepted April 1, 2014.

Please include this information when citing this paper: DOI: 10.3171/2014.4.SPINE14269.

Address correspondence to: Michael G. Kaiser, M.D., Columbia University, Neurological Surgery, The Neurological Institute, 710 W. 168th St., New York, NY 10032. email:mgk7@ columbia.edu. 